\title{
Anti-CGRP Monoclonal Antibodies: the Next Era of Migraine Prevention?
}

\author{
Amy R. Tso, $M D^{1,2}$ \\ Peter J. Goadsby, MD PhD ${ }^{1,2, *}$
}

\author{
Address \\ ${ }^{1}$ Basic and Clinical Neuroscience, Institute of Psychiatry, Psychology and \\ Neuroscience, King's College London, London, UK \\ ${ }^{*}, 2$ NIHR - Wellcome Trust King's Clinical Research Facility, King's College Hospital, \\ Wellcome Foundation Building, London, SE5 9PJ, UK \\ Email: peter.goadsby@kcl.ac.uk
}

Published online: 27 June 2017

(C) The Author(s) 2017. This article is an open access publication

This article is part of the Topical Collection on Headache

Keywords Migraine $\cdot$ Preventive $\cdot$ Treatment $\cdot$ Antibody $\cdot$ CGRP

\section{Opinion statement}

Migraine is a very disabling disorder with severe impact on patients' lives and substantive costs to society in terms of healthcare costs and lost productivity. Prevention is a key component of migraine therapy, and while numerous preventive options exist, each is burdened by either troublesome side effects or insufficient efficacy. All migraine preventives currently in clinical use were licensed for other purposes and, by chance, have efficacy against migraine. As our understanding of migraine has evolved, calcitonin gene-related peptide (CGRP) has moved to the forefront as a neuropeptide central to migraine pathophysiology. Six small molecule CGRP receptor antagonists were shown to be effective for acute treatment of migraine; two were stopped for hepatotoxicity or one for formulation concern issues and one is now in phase III. Monoclonal antibodies against CGRP or the CGRP receptor have a longer duration of action and have been investigated for migraine prevention. Four are in development and three have completed phase II and one phase III trials; every reported study has been positive. Furthermore, no safety issues have arisen to date, including hepatic or cardiovascular effects, and initial tolerability appears to be excellent. Monoclonal antibodies antagonizing the CGRP pathway represent a novel approach to prevention: a mechanism-specific migraine-targeted therapy. While we must await the results of all the phase III trials, cautious excitement seems warranted as we enter a new era of better tolerated, well-understood, bespoke migraine treatment for this common and disabling neurological disorder. 


\section{Introduction}

Migraine is one of the most prevalent and disabling disorders in the world, yet its pathophysiology remains incompletely understood [1]. Perhaps relating to this, no preventive treatments that are currently in clinical use were developed specifically for migraine [2]. For acute treatment, the only class of agents developed specifically for migraine, the triptans, was in fact thought to act via its vasoconstrictive properties [3] based on the prevailing view at the time that migraine was a vascular disorder [4]. It is now clear that vasodilation is neither necessary nor sufficient for migraine pain, and migraine is now understood to be a complex neuronal disorder with vascular epiphenomenon $[5 \bullet \bullet]$.

The need for improved preventive treatments for migraine is apparent: in the 2015 Global Burden of Disease Study, migraine was the seventh leading cause of disability globally and the leading neurological cause of disability, accounting for over half of the years lost to disability from all neurological disorders [6]. In the USA, the estimated direct healthcare expenditure on migraine is approximately $\$ 9$ billion per year [7] with indirect costs due to lost productivity doubling that figure [8]. Although numerous preventive treatment options exist [2], their utility is often limited by intolerable side effects such as cognitive slowing, drowsiness, or weight gain In general, patient adherence is low due to such side effects or insufficient efficacy $[9,10]$

Research is ongoing to address this unmet need for better prevention with fewer side effects. Advances in our understanding of migraine pathophysiology have led to new approaches such as neuromodulation and new pharmacologic targets $[11,12]$, and perhaps none have been as promising as calcitonin gene-related peptide (CGRP).

\section{Calcitonin gene-related peptide}

CGRP is a 37-amino acid neuropeptide that is widely distributed throughout the central and peripheral nervous systems [13, 14]. CGRP is present in sensory neurons, including in the trigeminal ganglion and nerve endings as well as

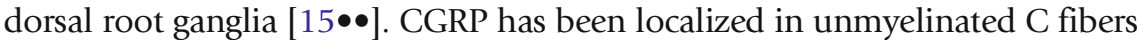
and small myelinated A $\delta$ fibers, which are involved in pain transmission, and is co-expressed with serotonin $5-\mathrm{HT}_{1 \mathrm{~B}}$ and $5-\mathrm{HT}_{1 \mathrm{D}}$ receptors [16, 17]. Immunohistochemistry studies in rats have shown CGRP is present centrally in brain structures including the hypothalamus, thalamus, and cerebellum [18], and in humans, CGRP binds densely in the cerebellum [19].

CGRP exists in $\alpha$ and $\beta$ isoforms. The main isoform expressed in the trigeminovascular system and in the brain is $\alpha$ CGRP, which is formed from alternative splicing of the calcitonin gene. The $\beta$ isoform is transcribed from a different gene and differs from $\alpha$ CGRP by three amino acids. It is expressed primarily in the enteric nervous system where it has distinct physiologic functions such as inhibiting gastric acid secretion [18].

CGRP binds to a G-protein coupled receptor formed by two subunits: calcitonin receptor-like receptor (CLR) and receptor activity-modifying protein 1 (RAMP1) [20]. Outside of the nervous system, the CGRP receptor is also found throughout the arterial system in the smooth muscle cell layer, including the cardiovascular and cerebrovascular systems, as well as in the adrenal glands, kidneys, and pancreas [16, 21].

In addition to being a potent vasodilator [22], evidence suggests that CGRP plays an important role in migraine pathophysiology. During spontaneous migraine attacks, CGRP concentrations measured from the external jugular vein rise [23] and CGRP serum levels decrease after administration of triptans in parallel with symptomatic relief $[24,25]$. Serum CGRP levels are elevated 
interictally in chronic migraine and to a lesser extent in episodic migraine [26]. Lastly, intravenous infusion of CGRP triggers attacks in migraineurs that are indistinguishable from spontaneous attacks $[27,28]$.

Antagonism of the CGRP pathway has been pursued as a new strategy for both acute and preventive treatment of migraine with promising results [12].

\section{Clinical trials}

The CGRP mechanism can be antagonized by targeting either the peptide or its receptor with either small molecule antagonists or monoclonal antibodies. This was first attempted for acute treatment of migraine. Several antagonists of the CGRP receptor including olcegepant (BIBN 4096 BS), telcagepant (MK-0974), MK-3207, BI 44370 TA, and BMS-927711 resulted in significantly higher painfree rates at $2 \mathrm{~h}$ when compared to placebo [29-33]. Unfortunately, development was complicated by pharmacokinetic issues and for telcagepant and MK3207 by hepatotoxicity. Ubrogepant is still under development for acute treatment [34] and atogepant for prevention (NCT02848326). Despite initial setbacks, these clinical trials have provided the proof of principle that targeting the CGRP pathway can effectively treat migraine.

Telcagepant was also investigated for prevention of episodic migraine [35]. Subjects with 3 to 14 days of headache during a 4-week baseline period were randomized to receive a daily dose of telcagepant 140 or $280 \mathrm{mg}$ or placebo for 12 weeks. The trial was terminated prematurely due to hepatotoxicity concerns; 13 patients in the telcagepant group and none in the placebo arm had derangement of liver function tests greater than three times the upper limit of normal. At the time of termination, all patients $(n=660)$ had been randomized, most had completed 1 month of treatment $(n=593)$, and some had completed 2 months of treatment $(n=312)$. Efficacy analysis could not be performed as originally planned, but the data suggested a reduction in the primary efficacy endpoint, mean monthly headache days, in the telcagepant groups compared to placebo after 1 month.

Monoclonal antibodies have been used increasingly for treatment of neurological disorders [36, 37], and migraine has been no exception. Monoclonal antibodies have a long half-life that makes them suitable for therapies requiring chronic activity such as migraine prevention. Furthermore, their long duration of action allows for less frequent dosing, e.g., once or twice monthly. Finally, antibodies are highly specific, allowing for highly selective targeting of either CGRP or its receptor.

Four monoclonal antibodies are currently in development for migraine prevention: three against CGRP itself: galcanezumab (LY2951742), eptinezumab (ALD403), and fremanezumab (TEV-48215) and one against the CGRP receptor erenumab (AMG-334). Results from phase II trials have been published for all four compounds (Table 1), and phase III trials are underway or completed. Phase III results have not been published to date.

Galcanezumab (LY2951742): The first phase II clinical trial results to be published were for Eli-Lilly's galcanezumab [38]. This study randomized patients with episodic migraine (4 to 14 headache days in 4-week baseline period) to galcanezumab $150 \mathrm{mg}$ subcutaneously versus placebo every 2 weeks for 12 weeks. Primary efficacy endpoint was the change in number of migraine 


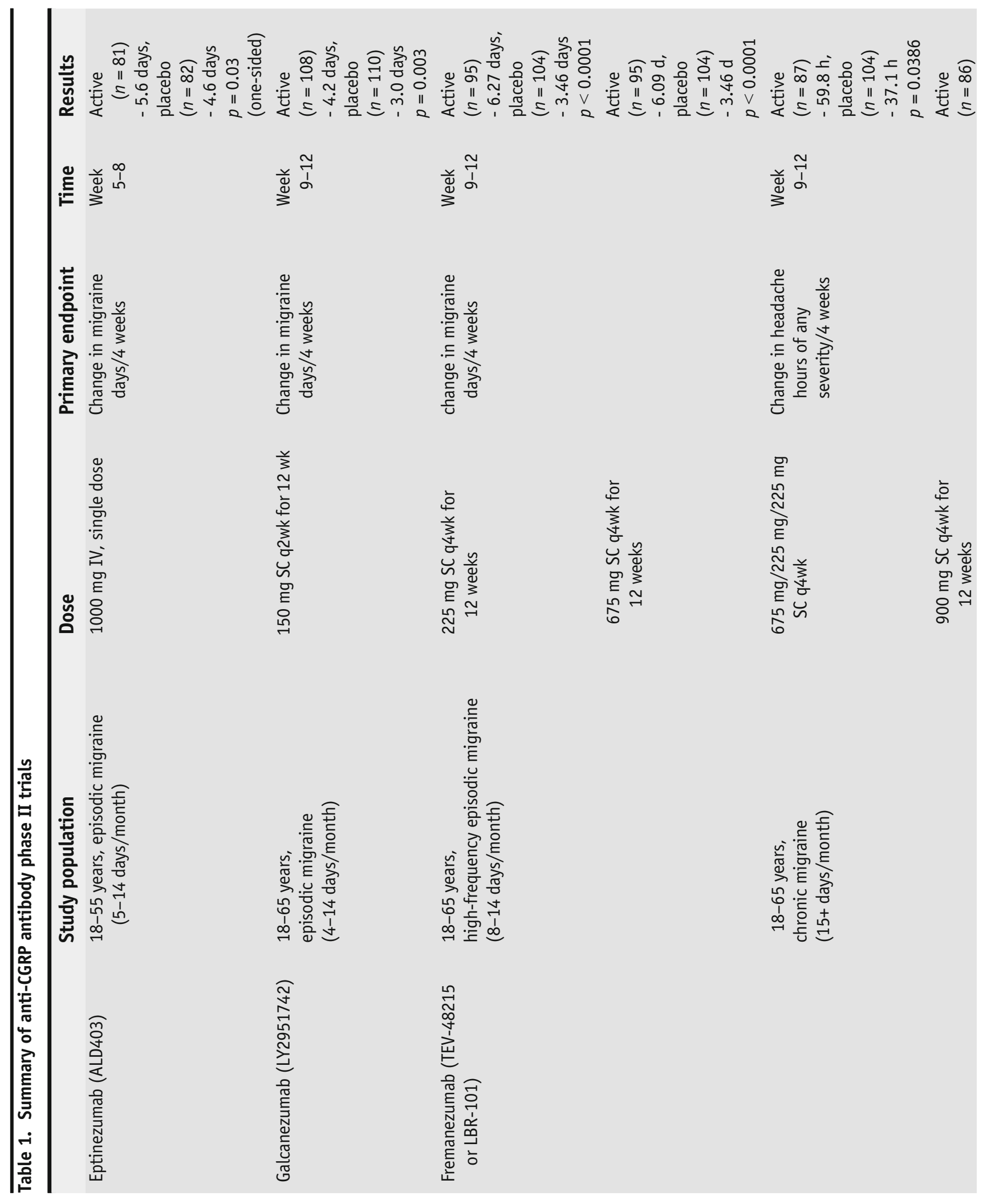




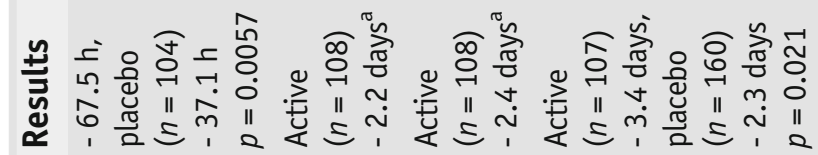

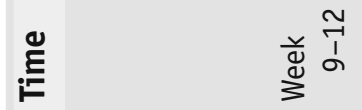

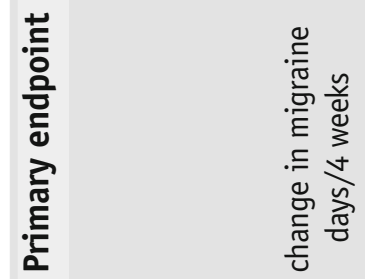

ญั

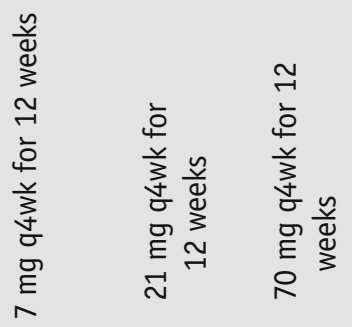

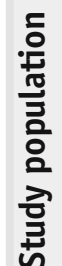

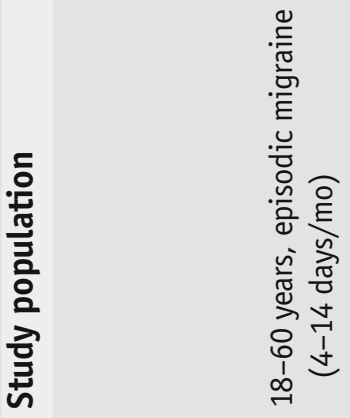

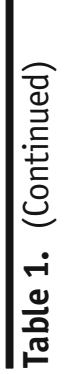

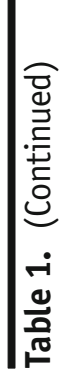



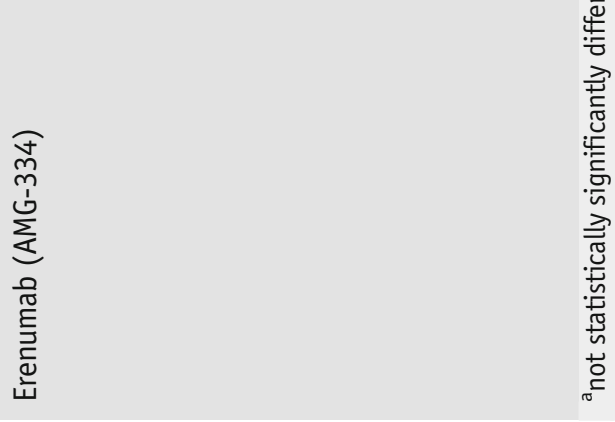


days during the third 4-week treatment period (weeks 9-12) compared to the baseline period. The mean change in migraine headache days was significantly different in the galcanezumab group compared to the placebo group $(-4.2$ versus -3.0 days, respectively; least squares mean difference $1.2, p=0.0030$ ).

Eptinezumab (ALD-403): Alder Biopharmaceuticals took a slightly different approach with eptinezumab, reasoning that intravenous administration would result in rapidly efficacious dosing with immediate physiological effect. Patients with episodic migraine (5 to 14 headache days in 4-week baseline period) were randomized to either a single dose of monthly intravenous eptinezumab $1000 \mathrm{mg}$ or placebo. The primary efficacy endpoint was the change in number of migraine days during weeks 5-8 compared to the baseline period. With a one-sided $p$ value (pre-specified), eptinezumab resulted in significantly fewer migraine days compared to placebo ( -5.6 versus -4.6 days, respectively; difference $1.0, p=0.0306$ ) [39].

fremanezumab (TEV-48215 or LBR-101): Teva Pharmaceuticals investigated fremanezumab in two separate trials for patients with either high-frequency episodic migraine or chronic migraine $[40,41]$. Patients with 8 to 14 headache days in 4-week baseline period were randomized to subcutaneous injections of either fremanezumab 225 or $675 \mathrm{mg}$ or placebo every 4 weeks for 12 weeks. Primary efficacy endpoint was the change in number of migraine days during the third 4-week treatment period (weeks 9-12) compared to the baseline period. The least square mean reduction in migraine days was significantly greater compared to placebo for both the fremanezumab $225 \mathrm{mg}$ ( -6.27 versus -3.46 days; difference 2.81 days, $p<0.0001)$ and $675 \mathrm{mg}$ doses $(-6.09$ versus -3.46 days; difference 2.64 days, $p<0.0001$ ). Of note, in contrast to the previous two studies, patients were not excluded for use of a migraine preventive; use of one preventive was allowed provided the dose had been stable for 2 months prior to screening.

For the chronic migraine trial, patients were randomized to either placebo or one of two fremanezumab doses given every 4 weeks for 12 weeks: $675 \mathrm{mg}$ loading dose followed by two $225 \mathrm{mg}$ doses or three doses of $900 \mathrm{mg}$. Primary efficacy endpoint was change in hours of headache of any severity during the third 4-week treatment period (weeks 9-12) compared to the baseline period. The least square mean reduction in headache hours of any severity was significantly greater compared to placebo for both the fremanezumab $675 \mathrm{mg} /$ $225 \mathrm{mg} / 225 \mathrm{mg}(-59.8$ versus $-37.1 \mathrm{~h}$; difference $22.7 \mathrm{~h}, p=0.0386)$ and $900 \mathrm{mg}$ doses ( -67.5 versus $-37.1 \mathrm{~h}$; difference $30.4 \mathrm{~h}, p=0.0057)$. Use of up to two preventives was permitted provided the doses were stable for at least 3 months. Of note, although chronic migraine is defined as 15 or more days of headache per month, the mean number of headache days per month in the study population was approximately 16 . Thus, the results may not be generalizable to patients with daily or near daily headache.

Erenumab (AMG-334): Lastly, Amgen has developed a monoclonal antibody against the CGRP receptor, erenumab, in contrast to the other three antibodies that are targeted at the CGRP molecule itself. Patients with episodic migraine (4 to 14 headache days in 4-week baseline period) were randomized to either placebo or one of three doses of erenumab $(7,14$, or $70 \mathrm{mg})$ subcutaneously every 4 weeks for 12 weeks. Primary efficacy endpoint was the change in number of migraine days during the third 4-week treatment period (weeks 912) compared to the baseline period. The least square mean change in migraine 
headache days was significantly different from the placebo group only for the highest dose, erenumab $70 \mathrm{mg}$ ( -3.4 versus -2.3 days; difference 1.1 days, $p=0.021)[42]$.

Initial safety and tolerability data from phase II trials appears excellent for the anti-CGRP monoclonal antibodies. No clinically significant change in vitals or ECGs was observed. Importantly, no change in hepatic enzymes judged to be treatment-related was seen with any of the monoclonal antibodies, in contrast to the small molecule CGRP receptor antagonists telcagepant and MK-3207. Adverse events were reported in a similar proportion of patients in the placebo and treatment groups. The most common treatment-related adverse event was injection site reaction of mild to moderate severity with subcutaneous injections; no intravenous infusion reactions were seen with eptinezumab. No treatment-related serious adverse events were reported.

Although all the monoclonal antibodies have been humanized to reduce immunogenicity, antibodies against these treatments can still form. All studies assessed for the presence of anti-drug antibodies, which were sometimes present before treatment. Anti-drug antibodies did not appear to affect drug concentration, efficacy, or adverse events.

All of the phase II trials administered treatment for 3 months with the exception of eptinezumab, which administered a single monthly dose. Thus, long-term safety is entirely unknown at this time. Open-label treatment phases lasting 1 year or longer will provide essential, longer-term safety and tolerability data.

The full range of CGRP's physiologic functions is complex [43]. CGRP is a potent vasodilator, and thus, a theoretical risk exists that CGRP blockade could hinder vasodilation in physiologically appropriate situations such as cardiac or cerebrovascular ischemia. Indeed, animal data suggests that CGRP plays a protective role against cardiac ischemia, cerebrovascular ischemia, and reperfusion injury and vasospasm after subarachnoid hemorrhage [44•]. Additionally, since antibodies have a relatively long half-life, any untoward effects could not be quickly reversed.

Although no cardiovascular effects have been seen to date, the incidence of cardiovascular or cerebrovascular disease is very low in the populations studied; the mean age in the various trials ranged from 39 to 43 years. Much larger populations would be needed to see the effect of CGRP blockade on very rare events, and this would likely only be achieved with post-marketing surveillance. Furthermore, the potential for long-term effects of chronic CGRP inhibition over years even without overt ischemia is entirely unknown.

Lastly, CGRP receptors are found outside of the nervous and vascular systems, including in the adrenal glands, kidneys, pancreas, and bone. The effect of chronic CGRP antagonism on other organs is unknown. 
antibodies is a novel approach in migraine prevention. All four monoclonal antibodies in development have had positive phase II trials. In addition, it appears that efficacy might be seen more quickly with these antibodies than with current preventive options, which typically require up to 8 weeks of treatment, although this must be interpreted with caution. As prespecified additional endpoints, the primary outcome variable was also measured after the first and second treatment cycles (at weeks 4 and 8) in both of the fremanezumab trials; a significantly greater reduction compared with placebo was seen at both time points. Likewise, the erenumab $70 \mathrm{mg}$ group, the only dose significantly different from placebo at 12 weeks, also showed a significant reduction in migraine days compared to placebo at weeks 4 and 8 . A single dose of eptinezumab resulted in a significant reduction in migraine days in weeks 5 to 8 , albeit with a oneside $p$ value. A post hoc analysis conducted for the fremanezumab chronic migraine trial showed a significant reduction in number of headache hours compared to placebo within the first week of treatment [45].

Monoclonal antibodies are large molecules that cross the blood-brain barrier in a small ratio of 1:1000 [46], although in individual patients, the ratio may favor penetration more [47]. Thus, their site of action in migraine prevention is unclear. Additionally, while most acute treatments for migraine have the potential to worsen migraine with frequent use, antagonism of the CGRP pathway is effective both acutely and chronically for prevention. Thus, the efficacy of CGRP antagonists raises interesting questions about migraine pathophysiology and much remains to be understood.

The cost of treatment, once the monoclonal antibodies become commercially available, will certainly be high. In a healthcare system of limited resources, this cost will need to be balanced with the magnitude of benefit. The primary endpoint of migraine days is not a useful clinical measure since it presents the average of those that do well and those that do poorly. In line with this, trials also analyzed the 50, 75, or $100 \%$ responder rates, the proportion of patients achieving the respective reduction in the primary outcome, either as exploratory endpoints or in post hoc analyses. Most trials found significantly higher responder rates compared with placebo at week 12 and often earlier. An important task will be to attempt to identify patients more likely to benefit so personalized therapy can begin to offset the cost of the treatments by minimizing the number of patients treated who have no useful response.

An important group of patients, those that failed more than two preventive categories, was largely excluded from the trials, and thus, it is unknown what benefit this population would derive. While their exclusion from initial trials may be warranted to maximize sensitivity to detecting efficacy, from a clinical perspective, this group is of particular interest. Patients seen at specialty headache centers are often medically partially refractory, having failed a number of preventives with limited remaining options. This group potentially stands to benefit the most from a novel, migraine-specific mechanism.

While the long-term safety profile of the anti-CGRP antibodies remains to be seen, a well-tolerated treatment targeting a migraine-specific mechanism for the first time represents the most significant advance in migraine therapy in decades. A new era of migraine prevention is on the horizon, an exciting development for clinicians and patients alike. 


\section{Compliance with Ethical Standards}

\section{Conflict of Interest}

Amy R. Tso declares no conflict of interest.

Peter J. Goadsby has received grants and personal fees from Amgen and Eli-Lilly and Company and personal fees from Alder Biopharmaceuticals, Novartis, Teva Pharmaceuticals during the conduct of the study. Dr. Goadsby has also received personal fees from Akita Biomedical, Avanir Pharma, Cipla Ltd., Dr. Reddy's Laboratories, Electrocore LLC, Pfizer Inc., Promius Pharma, Quest Diagnostics, Scion, Trigemina Inc., MedicoLegal work, Journal Watch, Upto-Date, Oxford University Press, Massachusetts Medical Society, outside the submitted work. In addition, Dr. Goadsby has a patent Magnetic stimulation for headache pending to eNeura.

\section{Human and Animal Rights and Informed Consent}

This article does not contain any studies with human or animal subjects performed by any of the authors.

\section{Open Access}

This article is distributed under the terms of the Creative Commons Attribution 4.0 International License (http://creativecommons.org/licenses/by/4.0/), which permits unrestricted use, distribution, and reproduction in any medium, provided you give appropriate credit to the original author(s) and the source, provide a link to the Creative Commons license, and indicate if changes were made.

\section{References and Recommended Reading}

Papers of particular interest, published recently, have been highlighted as:

- Of importance

$\bullet \quad$ Of major importance

1. Goadsby PJ, Lipton RB, Ferrari MD Migraine-current understanding and treatment. N Engl J Med. 2002;346:257-70.

2. Goadsby PJ, Sprenger T. Current practice and future directions in the management of migraine: acute and preventive. Lancet Neurol. 2010;9:28598.

3. Humphrey PPA, Feniuk W, Perren MJ, Beresford IJM, Skingle M, Whalley ET. Serotonin and migraine. Ann N Y Acad Sci. 1990;600:587-98.

4. Graham JR, Wolff HG. Mechanism of migraine headache and action of ergotamine tartrate. Arch Neurol Psychiatr. 1938;39:737-63.

5.• Goadsby PJ, Holland PR, Martins-Oliveira M, Hoffmann J, Schankin C, Akerman S. Pathophysiology of Migraine-a disorder of sensory processing. Physiol Rev. 2017;97:553-622.

Comprehensive review of migraine pathophysiology.

6. Disease GBD, Injury I, Prevalence C. Global, regional, and national incidence, prevalence, and years lived with disability for 310 diseases and injuries, 19902015: a systematic analysis for the Global Burden of Disease Study 2015. Lancet. 2016;388(10053):1545602.

7. Raval AD, Shah A. National trends in direct health care expenditures among US adults with migraine: 2004 to 2013. J Pain. 2017;18:96-107.

8. Munakata J, Hazard E, Serrano D, Klingman D, Rupnow MF, Tierce J, et al. Economic burden of transformed migraine: results from the American Migraine Prevalence and Prevention (AMPP) Study. Headache. 2009;49:498-508.

9. Blumenfeld AM, Bloudek LM, Becker WI, Buse DC, Varon SF, Maglinte GA, et al. Patterns of use and reasons for discontinuation of prophylactic medications for episodic migraine and chronic migraine: results from the second international burden of migraine study (IBMS-II). Headache. 2013;53(4):644-55.

10. Hepp Z, Dodick DW, Varon SF, Gillard P, Hansen RN, Devine EB. Adherence to oral migraine-preventive 
medications among patients with chronic migraine. Cephalalgia. 2015;35(6):478-88.

11. Tso AR, Goadsby PJ. New targets for migraine therapy. Curr Treat Options Neurol. 2014;16:318.

12. Goadsby PJ. Bench to Bedside Advances in the twentyfirst Century for primary headache

disorders-migraine treatments for migraine patients. Brain. 2016;139:2571-7.

13. Amara SG, Jonas V, Rosenfeld MG, Ong ES, Evans RM. Alternative RNA processing in calcitonin gene expression generates mRNAs encoding different polypeptide products. Nature. 1982;298:240-4.

14. Rosenfeld MG, Mermod JJ, Amara SG, Swanson LW, Sawchenko PE, Rivier J, et al. Production of a novel neuropeptide encoded by the calcitonin gene via tissue specific RNA processing. Nature. 1983;304:129-35.

$15 . \bullet$ Edvinsson L. CGRP receptor antagonists and antibodies against CGRP and its receptor in migraine treatment. Br J Clin Pharmacol. 2015;80:193-9.

Comprehensive review of CGRP pharmacology.

16. Eftekhari S, Edvinsson L. Possible sites of action of the new calcitonin gene-related peptide receptor antagonists. Ther Adv Neurol Disord. 2010;3:369-78.

17. Hou M, Kanje M, Longmore J, Tajti J, Uddman R, Edvinsson L. 5- $\mathrm{HT}_{1 \mathrm{~B}}$ and 5- $\mathrm{HT}_{1 \mathrm{D}}$ receptors in the human trigeminal ganglion: co-localization with calitonin gene-related peptide, substance $\mathrm{P}$ and nitric oxide synthase. Brain Res. 2001;909:112-20.

18. Van Rossum D, Hanisch UK, Quirion R. Neuroanatomical localization, pharmacological characterization and functions of CGRP, related peptides and their receptors. Neurosci Biobehav Rev. 1997;21:649-78.

19. Tschopp FA, Henke H, Petermann JB, Tobler PH, Janzer R, Hokfelt T, et al. Calcitonin gene-related peptide and its binding sites in the human central nervous system and pituitary. Proc Natl Acad Sci U S A. $1985 ; 82: 248-52$.

20. McLatchie LM, Fraser NJ, Main MJ, Wise A, Brown J, Thompson N, et al. RAMPs regulate the transport and ligand specificity of the calcitonin-receptor-like receptor. Nature. 1998;393:333-9.

21. Wimalawansa SJ. Calcitonin gene-related peptide and its receptors: molecular genetics, physiology, pathophysiology, and therapeutic potentials. Endocr Rev. 1996; 17:533-85.

22. Edvinsson L, Ekman R, Jansen I, McCulloch J, Uddman R. Calcitonin gene-related peptide and cerebral blood vessels: distribution and vasomotor effects. J Cereb Blood Flow Metab. 1987;7:720-8.

23. Goadsby PJ, Edvinsson L, Ekman R. Vasoactive peptide release in the extracerebral circulation of humans during migraine headache. Ann Neurol. 1990;28:183-7.

24. Goadsby PJ, Edvinsson L. The trigeminovascular system and migraine: studies characterizing cerebrovascular and neuropeptide changes seen in humans and cats. Ann Neurol. 1993;33:48-56.

25. Juhasz G, Zsombok T, Jakab B, Nemeth J, Szolcsanyi J, Bagdy G. Sumatriptan causes parallel decrease in plasma calcitonin gene-related peptide
(CGRP) concentration and migraine headache during nitroglycerin induced migraine attack. Cephalalgia. 2005;25:179-83.

26. Cernuda-Morollon E, Larrosa D, Ramon C, Vega J, Martinez-Camblor P, Pascual J. Interictal increase of CGRP levels in peripheral blood as a biomarker for chronic migraine. Neurology. 2013;81:1191-6.

27. Lassen LH, Haderslev PA, Jacobsen VB, Iversen HK, Sperling B, Olesen J. CGRP may play a causative role in migraine. Cephalalgia. 2002;22:54-61.

28. Hansen JM, Hauge AW, Olesen J, Ashina M. Calcitonin gene-related peptide triggers migraine-like attacks in patients with migraine with aura. Cephalalgia. 2010;30:1179-86.

29. Connor KM, Shapiro RE, Diener HC, Lucas S, Kost J, Fan X, et al. Randomized, controlled trial of telcagepant for the acute treatment of migraine. Neurology. 2009;73:970-7.

30. Diener H-C, Barbanti P, Dahlof C, Reuter U, Habeck J, Podhorna J. BI 44370 TA, an oral CGRP antagonist for the acute treatment of migraine attacks: results from a phase II study. Cephalalgia. 2011;31:573-84.

31. Hewitt DJ, Aurora SK, Dodick DW, Goadsby PJ, Ge J, Bachman R, et al. Randomized controlled trial of the CGRP receptor antagonist, MK-3207, in the acute treatment of migraine. Cephalalgia. 2011;31:712-22.

32. Marcus R, Goadsby PJ, Dodick D, Stock D, Manos G, Fischer TZ. BMS-927711 for the acute treatment of migraine: a double-blind, randomized, placebo controlled, dose-ranging trial. Cephalalgia. 2014;34:114-25.

33. Olesen J, Diener HC, Husstedt IW, Goadsby PJ, Hall D, Meier U, et al. Calcitonin gene-related peptide receptor antagonist BIBN 4096 BS for the acute treatment of migraine. N Engl J Med. 2004;350:1104-10.

34. Voss T, Lipton RB, Dodick DW, Dupre N, Ge JY, Bachman R, et al. A phase IIb randomized, doubleblind, placebo-controlled trial of ubrogepant for the acute treatment of migraine. Cephalalgia. 2016;36:887-98.

35. Ho TW, Connor KM, Zhang Y, Pearlman E, Koppenhaver J, Fan X, et al. Randomized controlled trial of the CGRP receptor antagonist telcagepant for migraine prevention. Neurology (Minneap). 2014;83:958-66.

36. Foltz IN, Karow M, Wasserman SM. Evolution and emergence of therapeutic monoclonal antibodies: what cardiologists need to know. Circulation. 2013;127(22):2222-30.

37. Lutterotti A, Martin R. Getting specific: monoclonal antibodies in multiple sclerosis. Lancet Neurol. 2008;7(6):538-47.

38. Dodick DW, Goadsby PJ, Spierings ELH, Scherer JC, Sweeney SP, Grayzel DS. CGRP monoclonal antibody LY2951742 for the prevention of migraine: a phase 2, randomized, double-blind, placebo-controlled study. Lancet Neurol. 2014;13:885-92.

39. Dodick DW, Goadsby PJ, Silberstein SD, Lipton RB, Olesen J, Ashina M, et al. Randomized, double-blind, placebo-controlled, phase II trial of ALD403, an anti- 
CGRP peptide antibody in the prevention of frequent episodic migraine. Lancet Neurol. 2014;13:1100-7.

40. Bigal ME, Dodick DW, Rapoport AM, Silberstein SD, Ma Y, Yang R, et al. Safety, tolerability, and efficacy of TEV-48125 for preventive treatment of high-frequency episodic migraine: a multicentre, randomized, doubleblind, placebo-controlled, phase $2 \mathrm{~b}$ study. Lancet Neurol. 2015;14:1081-90.

41. Bigal ME, Edvinsson L, Rapoport AM, Lipton RB, Spierings ELH, Diener H-C, et al. Safety, tolerability, and efficacy of TEV-48125 for preventive treatment of chronic migraine: a multicentre, randomized, doubleblind, placebo-controlled, phase 2b study. Lancet Neurol. 2015;14:1091-100.

42. Sun H, Dodick DW, Silberstein S, Goadsby PJ, Reuter $\mathrm{U}$, Ashina $\mathrm{M}$, et al. A randomised, double-blind, placebo-controlled, phase 2 study to evaluate the efficacy and safety of AMG 334 for the prevention of episodic migraine. Lancet Neurol. 2016;15:382-90.
43. Russell FA, King R, Smillie SJ, Kodji X, Brain SD. Calcitonin gene-related peptide: physiology and pathophysiology. Physiol Rev. 2014;94(4):1099-142.

44. MaassenVanDenBrink A, Meijer J, Villalon CM, Ferrari MD. Wiping out CGRP: potential cardiovascular risks. Trends Pharmacol Sci. 2016;37(9):779-88.

Summary of cardiovascular and cerebrovascular effects of CGRP.

45. Bigal ME, Dodick DW, Krymchantowski AV, VanderPluym JH, Tepper SJ, Aycardi E, et al. TEV48125 for the preventive treatment of chronic migraine-efficacy at early time points. Neurology (Minneap). 2016;87:41-8.

46. Felgenhauer K. Protein size and cerebrospinal fluid composition. Klin Wochenschr. 1974;52(24):1158-64.

47. Pittock SJ, Lennon VA, McKeon A, Mandrekar J, Weinshenker BG, Lucchinetti CF, et al. Eculizumab in AQP4-IgG-positive relapsing neuromyelitis optica spectrum disorders: an open-label pilot study. Lancet Neurol. 2013;12(6):554-62. 